\title{
Simple DNA repeats and sex chromosome differentiation in Asellus aquaticus (Crustacea, Isopoda)
}

\author{
E. V. VOLPI, F. PELLICCIA †, V. LANZA†, R. BARZOTTI† \& A. ROCCHI*† \\ Istituto di Genetica Molecolare del CNR, Porto Conte Research and Training Laboratories, Alghero, †Dipartimento di \\ Genetica e Biologia Molecolare, Università La Sapienza', Ple Aldo Moro, 5, 00185 Roma, and $\ddagger$ Centro di Genetica \\ Evoluzionistica del CNR, Università 'La Sapienza', Roma, Italy
}

\begin{abstract}
The crustacean isopod species Asellus aquaticus does not usually have recognizable sex chromosomes. We previously identified a Y chromosome marked by two heterochromatic bands in some males of a population from the Sarno river near Naples. In this work we used oligonucleotide probes to test the presence and possible sex-specific distribution of five simple repeat motifs in the genome of male and female individuals from the Sarno population. The five oligonucleotide probes were hybridized to enzyme-restricted genomic DNAs and the chromosome location of two probes was tested using fluorescence in situ hybridization. Our results show that only the $(\mathrm{TCC})_{\mathrm{n}}$ repetitive simple sequence has a sex-specific hybridization pattern and presents a significant accumulation on the $\mathrm{Y}$ chromosome in the region included between the two heterochromatic areas. Moreover the GGAAT sequence is not present in the genome of $A$. aquaticus in any detectable quantity.
\end{abstract}

Keywords: Asellus, crustacean, isopod, sex chromosome, simple repeats.

\section{Introduction}

The existence of morphologically differentiated sex chromosomes in crustaceans has been revealed by simple karyological analyses in some 40 species only. Of the isopods, several species of marine asellotes of the Jaera genus exhibit female heterogamety with multiple sex chromosomes $\mathrm{ZW}_{1} \mathrm{~W}_{2}$ and one flabellifers shows male heterogamety with an $\mathrm{X} 0$ chromosome formula, whereas no cases of XY type male heterogamety have ever been observed (Ginsburger-Vogel \& Charniaux-Cotton, 1982; Legrand et al., 1987). However, it is worth pointing out that of the roughly 4000 species belonging to this order only about 60 have been karyotyped. Furthermore, differential staining or molecular hybridization techniques have hardly ever been applied.

The karyotype of the isopod crustacean Asellus aquaticus consists of eight pairs of homomorphic chromosomes in both sexes. The chromosomes of this species cannot be differentiated by G- or R-banding techniques, whereas a variable number of terminal heterochromatic areas associated with the nucleolar organizers can be detected using the $\mathrm{C}$-banding tech-

*Correspondence.

(c) 1995 The Genetical Society of Great Britain. nique. The heterochromatic areas fluoresce brightly when stained with the GC-specific fluorochrome chromomycin A3, remaining dark when stained with DAPI (Rocchi et al., 1980; Di Castro et al., 1983).

A heteromorphic chromosome pair was identified in several males from a population collected from the Sarno river near Naples. One chromosome shows two intercalary heterochromatic areas, one on each arm, which stain brightly with chromomycin $\mathrm{A} 3$; variant ribosomal sequences are associated with these areas (Volpi et al., 1992). This heterochromosome is inherited through the male line as a normal Y chromosome (Rocchi et al., 1984). Although the chromosomes in the heteromorphic pair often appear precociously separated in meiotic metaphase I, they do in fact retain the capacity to recombine during meiosis in the subterminal regions distal to the heterochromatic areas. Exchange also occurs very infrequently in the chromosome area situated between the two heterochromatic areas, thus giving rise to chromosomes displaying only one heterochromatic area. On the strength of these and other observations (Volpi et al., 1992), we may reasonably postulate an early stage of chromosome differentiation; that this differentiation does not involve chromosome rearrangements in the form of inversions but, probably, the transfer of heterochromatic and 
ribosomal sequences from telomeric regions to interstitial sites; and that this transfer could be favoured by the 'Rabl-orientation' that the chromosomes retain during interphase (Schweizer \& Loidl, 1987).

In recent years the existence of sex-specific distribution patterns for various simple, tandemly repeated DNA sequences has been demonstrated in a number of organisms. Although usually scattered in the genome, in these cases the simple sequences present accumulations on the heterochromosome thus contributing to the evolution of a morphologically differentiated sex chromosome pair (for reviews see Epplen, 1988; Nanda et al., 1991, 1992).

In a previous paper we demonstrated the presence of GATA repeats in the $A$. aquaticus genome and established the absence of their sex-linked distribution (Pelliccia et al., 1991).

In this study we used five oligonucleotide probes specific for simple repeat motifs such as CA, TCC, CGA, CCTG and GGAAT. The five probes were hybridized to enzyme-restricted genomic DNA of male and female individuals from the Sarno population and, for TCC and CA, the chromosome location was tested using fluorescence in situ hybridization.

Our results show that the repetitive simple sequence $(\mathrm{TCC})_{n}$ has a sex-specific hybridization pattern and a significant accumulation on the heterochromosome in a region situated between the two heterochromatic areas. Moreover the GGAAT sequence is not present in the genome of $A$. aquaticus in any detectable quantity.

\section{Materials and methods}

The research was carried out on a population of $A$. aquaticus collected from the Sarno river near Naples. The DNA was extracted separately from batches of 30 male or female individuals. Samples of DNA $(2 \mu \mathrm{g})$ were digested with six restriction endonucleases: BamHI, EcoRI, HindIII, PstI, SacI or SacII (Boehringer, Mannheim), then size-fractionated on a 0.8 per cent agarose gel and blotted to nylon filters.

Synthetic probes consisting of repeat arrays of the CA, TCC, CGA, CCTG and GGAAT simple sequences were generated by PCR as described by Ijdo et al. (1991). This method produces heterogeneous populations of molecules of various lengths, up to 25 $\mathrm{kb}$. The probes were labelled by the nick translation technique using $\left[\alpha^{32} \mathrm{P}\right] \mathrm{dATP}$ and $\left[\alpha^{32} \mathrm{P}\right] \mathrm{dCTP}$ (Amersham, UK). Filters were prehybridized at $66^{\circ} \mathrm{C}$ for $2 \mathrm{~h}$ in $5 \times$ Denhardt's, $6 \times \mathrm{SSC}, 0.5$ per cent SDS. Hybridization was carried out at the same temperature for $48 \mathrm{~h}$ in the same solution. The filters were washed with $2 \times \mathrm{SSC}, 0.1 \mathrm{SDS}$ at $66^{\circ} \mathrm{C}$ followed, for the $(\mathrm{CA})_{\mathrm{n}}$ probe only, by $1 \times$ SSC, 0.1 per cent SDS.

Chromosome preparations obtained from squashes of testes were hybridized in situ with two of the synthetic probes $(\mathrm{CA})_{\mathrm{n}}$ and $(\mathrm{TCC})_{\mathrm{n}}$. The probes were labelled with biotin-11-dUTP (Sigma) or biotin dATP (Gibco, BRL) by nick translation. Chromosome preparations were denatured in 70 per cent formamide $/ 2 \times \mathrm{SSC}$ at $70^{\circ} \mathrm{C}$ for $3 \mathrm{~min}$ and the hybridization was performed at $37^{\circ} \mathrm{C}$ in $4 \times \mathrm{SSC}, 20$ per cent formamide, 10 per cent $(\mathrm{w} / \mathrm{v})$ dextran sulphate and 0.3 $\mu \mathrm{L}$ of sonicated salmon sperm DNA. The washes after hybridization were at room temperature in 20 per cent formamide $/ 4 \times$ SSC (three times) followed by three washes in $4 \times \mathrm{SSC}, 0.1$ per cent Tween 20 at $42^{\circ} \mathrm{C}$. Biotin-labelled DNA was detected using FITCconjugated avidin (Vector Laboratories). The specimens were simultaneously stained with DAPI. Digital images were obtained using a computer-controlled Zeiss Axioscop epifluorescence microscope equipped with a CCD camera. Digital imaging and computer software have been previously described (Pelliccia $e t$ al., 1994).

\section{Results}

Southern blots, obtained with DNA from $A$. aquaticus males and females collected in the Sarno river and digested with restriction enzymes, were hybridized with five oligonucleotide probes consisting of CA, TCC, CGA, CCTG and GGAAT sequences repeated in tandem. Sequences homologous to the first four probes used were present in the genome of this organism. The (GGAAT) ${ }_{n}$ sequence was not detected in our conditions of hybridization. The $(\mathrm{CA})_{n}$ and $(\mathrm{TCC})_{\mathrm{n}}$ probes detected heterogeneous DNA fragments, most of which form a high molecular weight smear, and some discrete bands (Figs 1 and 2). Only the simple $(\mathrm{TCC})_{\mathrm{n}}$ sequence displays a sex-specific hybridization pattern, the male DNA differing from female DNA by exhibiting an extra band with all the restriction enzymes used. The supernumerary fragments are $7 \mathrm{~kb}$ long for the SacII enzyme, $6.3 \mathrm{~kb}$ for the HindIII enzyme, $6.2 \mathrm{~kb}$ for the BamHI and EcoRI enzymes, $5.6 \mathrm{~kb}$ for the Pst enzyme and $2.3 \mathrm{~kb}$ for the SacI enzyme (Fig. 1). The (CGA) and (CCTG) $)_{n}$ probes hybridized mainly to heterogeneous DNA fragments with all the enzymes used, forming smears between 2.5 and $15 \mathrm{~kb}$.

Subsequent to in situ hybridization with probe $(\mathrm{CA})_{\mathrm{n}}$ a scattered distribution of label is observed on all chromosomes; moreover, some hybridization signals are preferentially located in areas proximal to 
Fig. 1 Southern blot hybridization of genomic DNA of male $(\mathbf{M})$ and female (F) individuals of Asellus aquaticus digested with SacII (lanes 1), BamHI (lanes 2), SacI (lanes 3), EcoRI (lanes 4), HindIII (lane 5) and PstI (lane 6). The probe was the ${ }^{32} \mathrm{P}$-labelled $(\mathrm{TCC})_{\mathrm{n}}$ sequence. The arrow heads indicate the male-specific fragments. Lambda $H$ indIII fragments were used as size markers $(23.3,9.4,6.6,4.3,2.3$ and 2.0 $\mathrm{kb})$.

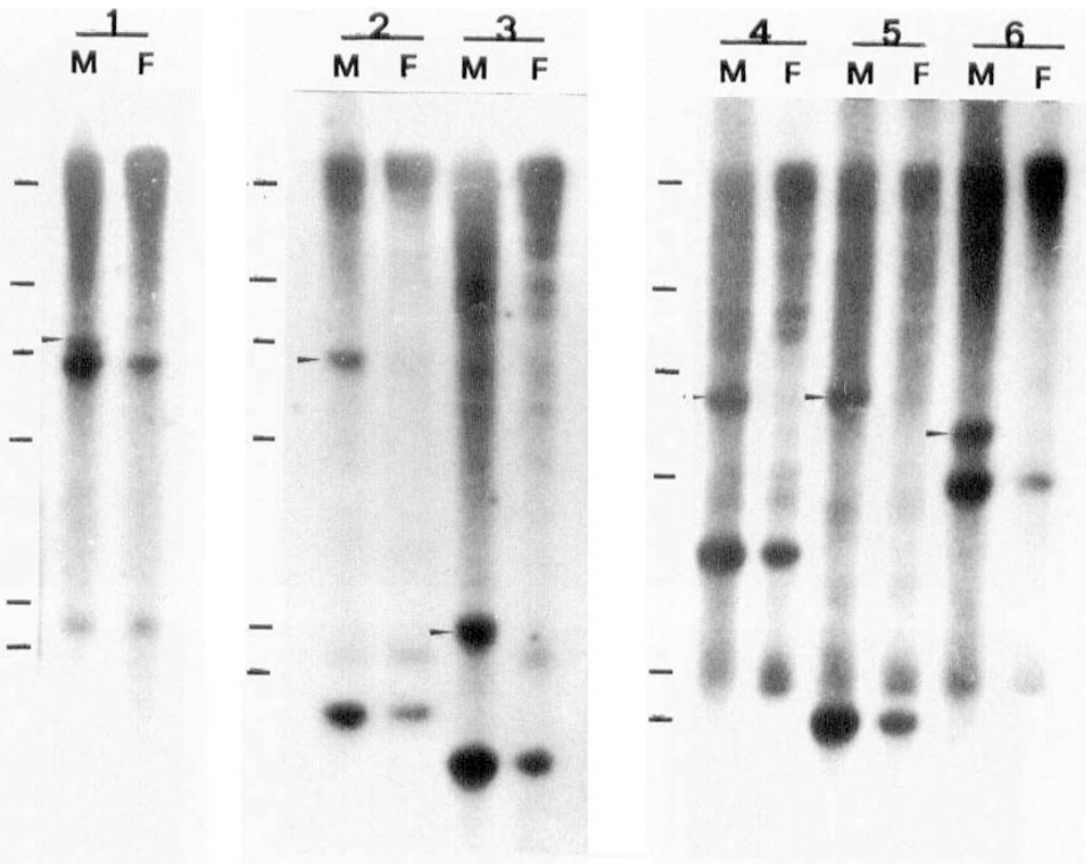

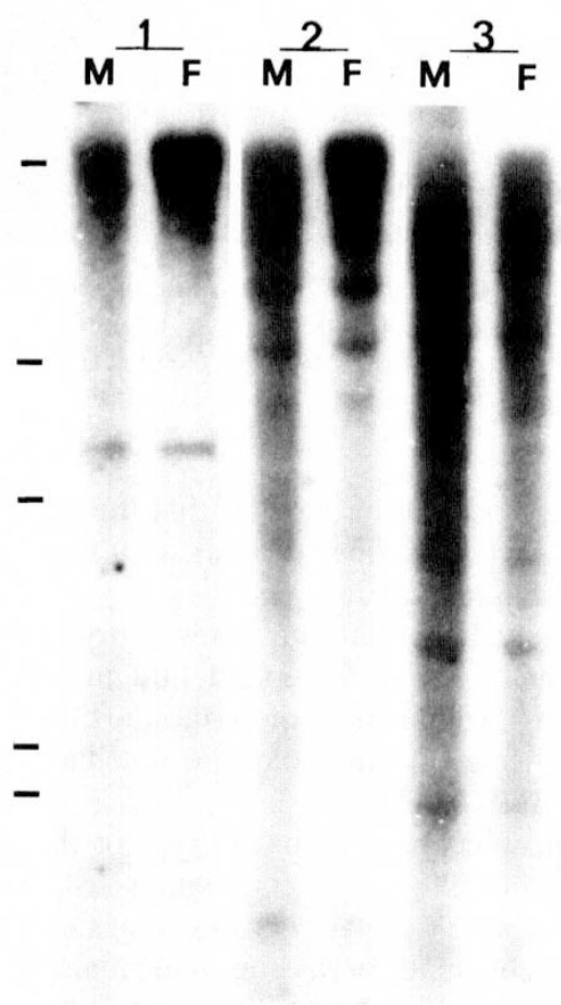

Fig. 2 Southern blot hybridization of genomic DNA of male (M) and female (F) individuals of Asellus aquaticus digested with BamHI (lanes 1), SacI (lanes 2) and HindIII (lanes 3). The probe was the ${ }^{32} \mathrm{P}$-labelled $(\mathrm{CA})_{n}$ synthetic simple sequence. Note the same pattern of bands for male and female individuals. Lambda HindIII fragments were used as size markers $(23.3,6.6,4.3,2.3$ and $2.0 \mathrm{~kb})$. the centromere of certain chromosomes and in at least one interstitial area. As it is impossible to identify most of the chromosomes and, moreover, polymorphism is also involved, examination of the specimens is by no means simple. With this probe the $\mathrm{Y}$ chromosome shows no particular label in the area lying between the two heterochromatic bands, whereas some signs of hybridization can be seen in one region located between the telomere and one of the two heterochromatic bands (Fig. 3d).

Hybridization with the (TCC $)_{n}$ probe yielded quantitatively poorer label than the $(\mathbf{C A})_{n}$ probe. Scattered hybridization signals were scant and some of them tended to localize in the areas near the telomeres and centromere of a few chromosomes. The Y chromosome shows a prominent signal in the area between the centromere and the smaller of the two interstitial heterochromatic bands, which is also the band situated further from the centromere. No other chromosome displays this type of label (Fig. 3a-b). Moreover, the meiotic I metaphases of individuals with heterochromosomes exhibit a heteromorphic tetrad in relation to this signal (Fig. $3 \mathrm{c}$ ).

\section{Discussion}

Simple tandemly repeated DNA sequences are present in all eukaryotic genomes examined (Nanda et al., 1991). Nearly all possible simple motifs occur 5-10 times more frequently than equivalent random motifs 

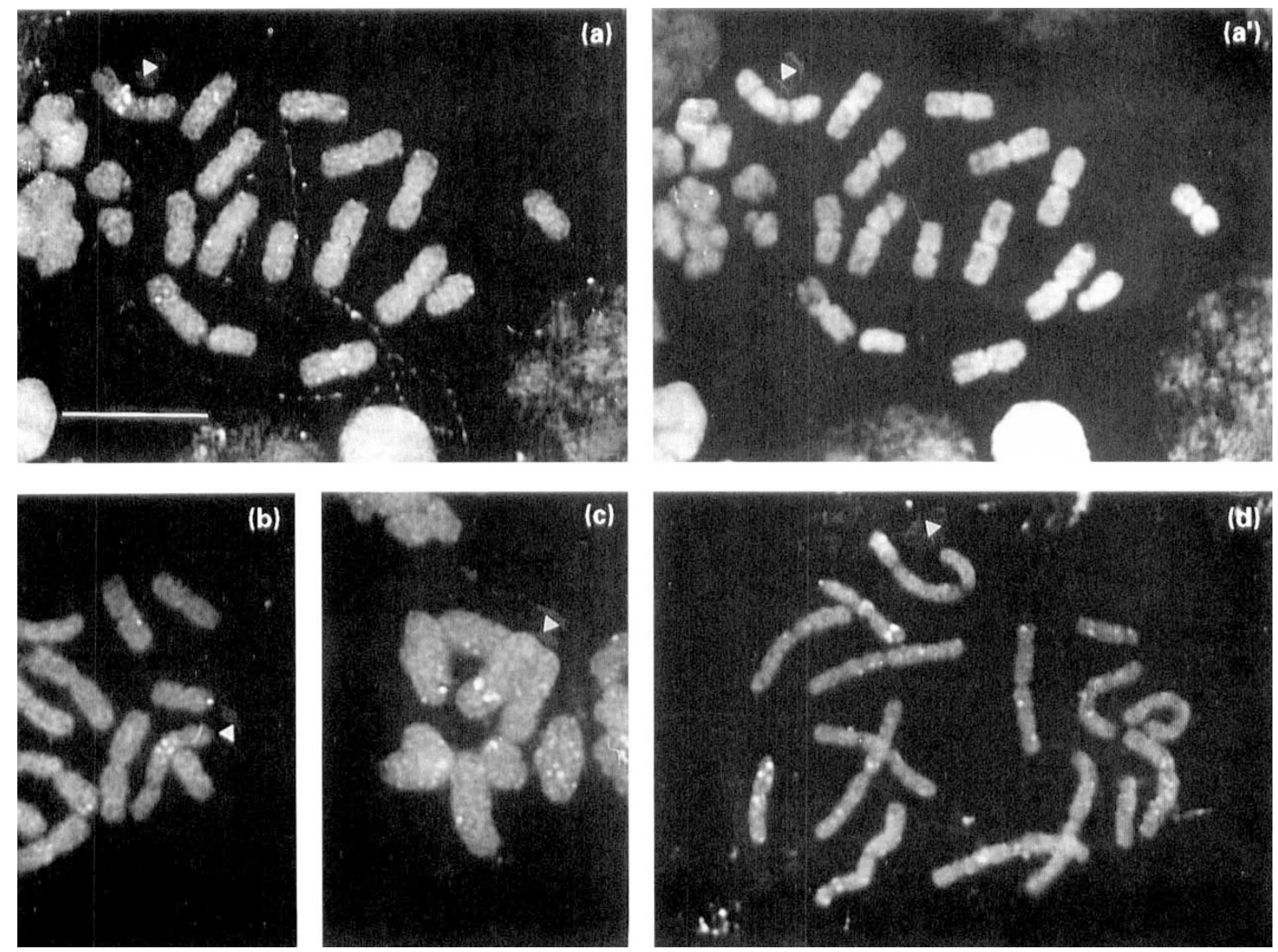

Fig. 3 In situ hybridization of spermatogonial (a, b, d) and meiotic I (c) metaphases of Asellus aquaticus. The probes were the biotin-labelled $(\mathrm{TCC})_{n}$ sequence $(\mathrm{a}, \mathrm{b}, \mathrm{c})$ and the biotin-labelled $(\mathrm{CA})_{\mathrm{n}}$ sequence $(\mathrm{d})$. The same spermatogonial metaphase is hybridized in situ (a) and stained with DAPI $\left(\mathrm{a}^{\prime}\right)$. The arrow heads indicate the Y chromosomes. Bar represents $10 \mu \mathrm{m}$.

in both coding and noncoding regions (Tautz et al., 1986). These sequences have been implicated in a variety of functions, although they might arise by DNA replication slippage or unequal crossing-over and have no primary function. Some simple sequences are sexspecifically organized and the evolution of morphologically differentiated sex chromosomes has been associated with their significant accumulation by some researchers (for reviews see Epplen, 1988; Nanda et al., 1992).

Accumulations of $(\mathrm{GATA})_{\mathrm{n}}$ and $(\mathrm{GACA})_{\mathrm{n}}$ sequences have been observed in the heterochromosomes of snakes (Jones \& Singh, 1985), rats (Schäfer et al., 1986) and a poeciliid fish (Nanda et al., 1990, 1991, 1992). Other poeciliid species harbour the GGAT and CA sex-specifically organized simple repeat motifs (Nanda et al., 1992). Moreover, long stretches of (TCC) $)_{n}$ simple repeats characterize bird W chromosomes (Nanda et al., 1991).
All these observations suggest that the sex chromosomes are favoured sites for the accumulation of a number of simple repeats.

It is widely held that the heteromorphism of sex chromosomes evolved independently in the various taxa, starting from a pair of homomorphic chromosomes and using various molecular mechanisms (for a review see Bull, 1983).

One typical mechanism for this type of chromosome diversification is the accumulation of repetitive elements. In fact, Y (or W) chromosomes often exhibit large heterochromatic areas consisting mainly of highly repeated DNA sequences (for a review see John, 1988). These sequences can be hundreds of base pairs long or simple motifs of fewer than 10 base pairs (e.g. Cooke, 1976; Nakahori, 1986).

The accumulation of these sequences resulting fundamentally from transposition and amplification processes is believed to take place at first on the $\mathrm{Y}$ (or 
W) chromosome in the vicinity of the sex determining region, favoured by the absence or low frequency of recombination events in this area.

By further inhibiting exchange, the heteromorphism thus acquired by the sex chromosome pair would lead to increasing isolation of the $\mathrm{Y}$ (or $\mathrm{W}$ ) chromosome, creating the possibility for further differentiation (Muller, 1964; Bull, 1983; Charlesworth, 1991).

In previous papers we observed that certain males in an $A$. aquaticus population collected from the Sarno river near Naples display a heteromorphic sex chromosome pair. The $\mathrm{Y}$ chromosome has two intercalary areas that harbour ribosomal variant sequences (Rocchi et al., 1984; Volpi et al., 1992). Meiotic recombination within the heteromorphic pair often occurs in the subterminal regions distal to the heterochromatic bands, but is very rarely observed in the region situated between them.

In this paper we demonstrate the presence of a further heteromorphism involving the $A$. aquaticus sex chromosome pair. Experiments by Southern and in situ hybridization demonstrate that the $\mathrm{Y}$ chromosome is enriched with $(\mathrm{TCC})_{n}$ simple repeats precisely in an area comprised between the centromere and one of the two heterochromatic bands. Thus the $(\mathrm{TCC})_{n}$ sequence plays a part in the evolution of the heteromorphic chromosome pair, its accumulation possibly being favoured by the scarcity of recombination events in this region which probably harbours the sex gene/genes and also contains the centromere. The area on the heterochromosome harbouring TCC simple repeat accumulation shows no colorimetric differentiation after C-banding or staining with specific base fluorochromes, and is thus not to be considered a classical heterochromatic region. The $(\mathrm{TCC})_{n}$ sequence is also present in other genome locations, both as relatively long stretches of TCC sequences and as relatively short TCC repeat arrays interspersed with other sequences.

In the case of the other simple repeats tested on the A. aquaticus genome, Southern blot analysis shows no sex-specific hybridization of the $(\mathrm{CGA})_{n},(\mathrm{CCTG})_{n}$ and $(\mathrm{CA})_{n}$ probes. The $(\mathrm{CA})_{n}$ simple repeat is found in all eukaryotic genomes examined, indicating extraordinary evolutionary conservation (e.g. Hamada et al., 1982). It has been speculated that it is involved in the regulation of gene expression as it can adopt Z-DNA conformation.

The (GGAAT) $)_{n}$ pentanucleotide does not seem to be present in the $A$. aquaticus genome. This repeat shows exceptional evolutionary conservation; centromeric localization of the repeat has been demonstrated in several organisms, and it has been suggested that the repeat also plays a role in the functional human centromere (Grady et al., 1992).

\section{Acknowledgements}

This work was supported by Ministero dell'Università e della Ricerca Scientifica (MURST), Italia and by the Consiglio Nazionale delle Ricerche (CNR), Italia. We thank the Cenci Bolognetti Foundation for supplying the ${ }^{32}$ P-labelled nucleotides.

\section{References}

BULl, J. J. 1983. Evolution of Sex Determining Mechanisms. Benjamin/Cummings, Menlo Park, CA.

CHARLESWORTH, B. 1991. The evolution of sex chromosomes. Science, 251, 1030-1033.

COOKE, H. J. 1976. Repeated sequence specific to human males. Nature, 262, 182-186.

DI CASTRO, M., PRANTERA, G., CIPRIANI, L. AND ROCCHI, A. 1983. Silver staining analysis of nucleolar organizer activity during spermatogenesis of Asellus aquaticus (Crustacea, Isopoda). Genetica, 60, 163-166.

EPPLEN, J. T. 1988. On the simple repeated GATA sequences in animal genomes: a critical reappraisal. J. Hered., 79, 409-417.

gisBuRger-Vogel, t. AND CharniauX-COtton, H. 1982. SeX determination. In: Bliss, D. E. (ed.) Biology of Crustacea, pp. 257-281. Academic Press, New York, London.

GRADY, D. L., RATLIFF, R. L., ROBINSON, D. L., MCCANLIES, E. C., MEYNE, J. AND MOYZIS, R. K. 1992. Highly conserved repetitive DNA sequences are present at human centromeres. Proc. Natl. Acad. Sci. U.S.A., 89, 1695-1699.

HAMADA, H., PETRINO, M. G. AND KaxunagA, T. 1982. A novel repeated element with Z-DNA-forming potential is widely found in evolutionarily diverse eukaryotic genomes. Proc. Natl. Acad. Sci. U.S.A., 79, 6465-6469.

IJDO, J. W., WELLS, R. A., BALDINI, A. AND REEDERS, S. T. 1991. Improved telomere detection using a telomere repeat probe (TTAGGG) $)_{n}$ generated by PCR. Nucl. Acids Res., 19, 4780 .

JOHN, в. 1988. The biology of heterochromatin. In: Verma R. S. (ed.) Heterochromatin: Molecular and Structural Aspects, pp. 1-147. Cambridge University Press, Cambridge.

JONES, K. W. AND SINGH, L. 1985. Snakes and the evolution of sex chromosomes. Trends Genet., 1, 55-61.

LEGRAND, J. J., LEGRAND-HAMELIN, E. AND JUCHAULT, P. 1987. Sex determination in Crustacea. Biol. Rev. Camb. Phil. Soc., 62, 439-470.

MULLER, H. J. 1964. The relation of recombination to mutational advance. Mutat. Res., 1, 2-9.

NAKAORI, Y., MITANI, K., YAMADA, M. AND NAGAKOME, Y. 1986. A human $Y$ chromosome specific repeated DNA family (DYZ1) consists of a tandem array of pentanucleotides. Nucl. Acids Res., 14, 7569-7580.

NANDA, I., FEICHTINGER, W., SCHMID, M., SCHRÖDER, J. H., ZISCHLER, H. AND EPPLEN, J. T. 1990. Simple repetitive sequences are associated with differentiation of sex chromosomes in the guppy fish. J. Mol. Evol., 30, 456-462. 
NANDA, 1., SCHARLT, M., FEICHTINGER, W., EPPLEN, J. T. AND SCHMID, M. 1992. Early stages of sex chromosome differentiation in fish as analysed by simple repetitive DNA sequences. Chromosoma, 101, 301-310.

NANDA, I., ZISCHLER, H., EPPLEN, C., GUTTENBACH, M. AND SCHMID, M. 1991. Chromosomal organization of simple repeat DNA sequences used for DNA fingerprinting. Electrophoresis, 12, 193-203.

PELliCCIA, F., DI CASTRO, M., LANZA, V., VOLPI, E. V. AND ROCCHI, A. 1991. GATA repeats in the genome of Asellus aquaticus (Crustacea, Isopoda). Chromosoma, 100, 152-155.

PELLICCIA, F., VOLPI, E. V., LANZA, V., GADDINI, L., BALDINI, A. AND ROCCHI, A. 1994. Telomeric sequences of Asellus aquaticus (Crust. Isop.). Heredity, 72, 78-80.

ROCCHI, A., PRANTERA, G. AND DI CASTRo, M. 1980. A study of heterochromatin of Asellus aquaticus (Crust. Isop.). Caryologia, 33, 401-409.
ROCCHI, A., PRANTERA, G., LANZA, V. AND DI CASTRO, M. 1984. Incipient sex chromosome differentiation in an isopod crustacean species, Asellus aquaticus. Chromosoma, 89 , 193-196.

SCHÄFER, R., ALI, S. AND EPPLEN, J. T. 1986. The organization of the evolutionarily conserved GATA/GACA repeats in the mouse genome. Chromosoma, 93, 502-510.

SCHWEIZER, D. AND LOIDL, J. 1987. A model for heterochromatin dispersion and the evolution of C-band patterns. In: Stahl, A., Luciani, J. M. and VagnerCapodanno, A. M. (eds) Chromosomes Today, vol. 9, pp. 61-74. Allen and Unwin, London.

TAUTZ, D., TRICK, M. AND DOVER, G. A. 1986. Cryptic simplicity in DNA is a major source of genetic variation. Nature, $\mathbf{3 2 2}$, 652-656.

VOLPI, E. V., PELLICCIA, F., LANZA, V., DI CASTRO, M. AND ROCCHI, A. 1992. Morphological differentiation of a sex chromosome and ribosomal genes in Asellus aquaticus (Crust. Isop.). Heredity, 69, 478-482. 